\title{
Uncertainty and Margin Study for IMRT, VMAT, and Proton Beam Therapy for Treatment After Radical Prostatectomy
}

\author{
Y. Cui \\ Thomas Jefferson University Hospitals
}

\author{
A. S. Harrison \\ Thomas Jefferson University Hospitals \\ M T. Studenski \\ Thomas Jefferson University Hospitals \\ T. N. Showalter \\ Thomas Jefferson University Hospitals
}

J. O. Deasy

Washington University, St Louis

Follow this and additional works at: https://jdc.jefferson.edu/bodinejournal

Part of the Oncology Commons

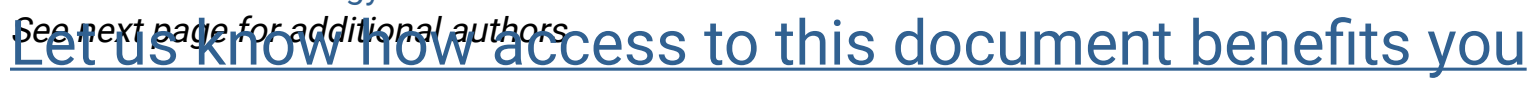

\section{Recommended Citation}

Cui, Y.; Harrison, A. S.; Studenski, M T.; Showalter, T. N.; Deasy, J. O.; Yu, Y.; Galvin, J. M.; and Xiao, Y. (2010) "Uncertainty and Margin Study for IMRT, VMAT, and Proton Beam Therapy for Treatment After Radical Prostatectomy," Bodine Journal: Vol. 3 : Iss. 1 , Article 26.

DOI: https://doi.org/10.29046/TBJ.003.1.025

Available at: https://jdc.jefferson.edu/bodinejournal/vol3/iss1/26

This Article is brought to you for free and open access by the Jefferson Digital Commons. The Jefferson Digital Commons is a service of Thomas Jefferson University's Center for Teaching and Learning (CTL). The Commons is a showcase for Jefferson books and journals, peer-reviewed scholarly publications, unique historical collections from the University archives, and teaching tools. The Jefferson Digital Commons allows researchers and interested readers anywhere in the world to learn about and keep up to date with Jefferson scholarship. This article has been accepted for inclusion in Bodine Journal by an authorized administrator of the Jefferson Digital Commons. For more information, please contact: JeffersonDigitalCommons@jefferson.edu. 


\section{Uncertainty and Margin Study for IMRT, VMAT, and Proton Beam Therapy for Treatment After Radical Prostatectomy}

Authors

Y. Cui, A. S. Harrison, M T. Studenski, T. N. Showalter, J. O. Deasy, Y. Yu, J. M. Galvin, and Y. Xiao 


\title{
Uncertainty and Margin Study for IMRT, VMAT, and Proton Beam Therapy for Treatment After Radical Prostatectomy
}

\author{
Cui, Y., ${ }^{1}$ Harrison, A.S., ${ }^{1}$ Studenski, M.T., ${ }^{1}$ Showalter, T.N.,, ${ }^{1}$ Deasy, J.O., ${ }^{2}$ Yu, Y., ${ }^{1}$ Galvin, J.M., ${ }^{1}$ Xiao, Y. \\ ${ }^{1}$ Department of Radiation Oncology, Thomas Jefferson University Hospitals, Philadelphia, PA \\ ${ }^{2}$ Washington University, Saint Louis, MO
}

\section{Purpose/Objective(s)}

To compare the uncertainties of $3 \mathrm{D}$ dose distributions, caused by the geometrical uncertainty of patient setup, in IMRT, VMAT, and proton plans for post-prostatectomy treatment. To test the effectiveness of a common margin recipe in these three types of treatment plans.

\section{Material/Methods}

Four prostate fossa patient datasets were included. For each case, three different plans were carried out: an IMRT plan of nine fields (XiO, Elekta), a VMAT plan, and a proton plan with two lateral active scanning beams (Oncentra, Nucletron). The plan robustness analysis function in CERR (Washington University, St. Louis, MO) software was used to simulate the DVH uncertainty with given systematic $(\Sigma)$ and random $(\sigma)$ shifts in three dimensions. Five different combinations of $\Sigma(2-4 \mathrm{~mm})$ and $\sigma(2-4 \mathrm{~mm})$ representing clinical situations were used for all plans. The DVH uncertainty range (upper and lower bounds) was generated by CERR for each setting of $\Sigma$ and $\sigma$ with a certain confidence level (95\% was used in this study). We tested CTV coverage using a common margin recipe $(2.5 \Sigma+0.7 \sigma)$ for all IMRT, VMAT, and proton plans.

\section{Results}

More than $98 \%$ of PTV was covered by $95 \%$ of prescription dose in all plans. The upper bound of PTV $\mathrm{V}_{95 \%}$ was close to $100 \%$ in all plans for all $\Sigma$ and $\sigma$ settings. The mean values of lower bound of PTV $\mathrm{V}_{95 \%}$ were $85.4 \%, 85.0 \%$, and $87.5 \%$ for IMRT, VMAT, and proton plans, respectively ( $p=0.03$ for IMRT vs. proton, paired samples $t$-test; $p=0.01$ for VMAT vs. proton; $p=0.36$ for IMRT vs. VMAT). The mean values of ranges (upper minus lower bound) for rectum $\mathrm{V}_{45 \mathrm{~Gy}}$ were 7.5\% (IMRT), $7.5 \%$ (VMAT), $15.6 \%$ (proton), and the mean values of ranges for bladder $\mathrm{V}_{40 \mathrm{~Gy}}$ were $6.2 \%$ (IMRT), 9.2\% (VMAT), $12.7 \%$ (proton). The proton plans exhibited significantly wider range of rectum and bladder DVHs than the other two treatment techniques ( $p<0.05$ for both). Even though the proton plans had lower rectum and bladder doses as compared with IMRT and VMAT, with the uncertainty, the upper bounds were approaching similar doses from IMRT and VMAT. Analysis of PTV V100\%, rectum $\mathrm{V}_{56 \mathrm{~Gy}}$, bladder $\mathrm{V}_{56 \mathrm{~Gy}}$ showed similar comparison results. The lower bound of CTV
$\mathrm{V}_{95 \%}$ was larger than $99.4 \%$ in all plans with the estimated $\Sigma$ and $\sigma$ from the margin recipe, showing the effectiveness of the margin recipe for IMRT, VMAT, and proton plans included in this study.

\section{Conclusion}

In this simulation of potential setup uncertainties, larger variation in DVH for bladder and rectum were observed with proton plans than with IMRT and VMAT plans, to the extent that might compromise the advantage of proton plans. The common margin recipe was validated as a method to assure adequate target volume coverage for IMRT, VMAT and proton plans studied. 